\title{
SURVIVABILITY ASSESSMENT OF FASTNET LIGHTHOUSE
}

\author{
Alessandro Antonini, University of Plymouth, alessandro.antonini@plymouth.ac.uk \\ Alison Raby, University of Plymouth, alison.raby@plymouth.ac.uk \\ Piermodesto Caputo, University of Bologna, piermodesto.caputo@studio.unibo.it \\ James Brownjohn, University of Exeter, j.brownjohn@exeter.ac.uk \\ Athanasios Papas, University College London, a.pappas@ucl.ac.uk \\ Dina D'Ayala, University College London, d.dayala@ucl.ac.uk
}

\section{INTRODUCTION AND OBJECTIVES}

Historic rock-mounted lighthouses play a vital role in the safe navigation around perilous reefs. However their longevity is threatened by the battering of waves. Virtual navigational aids such as GPS are fallible, and reliance on them can be disastrous. Mariners will therefore continue to need the physical visual aids of these strategic structures. After a site-specific extreme wave characterisation, the study evaluates the dynamic response of Fastnet Lighthouse (Figure 1) under the action of different wave loadings through a validated FEM numerical model. The aim of the study is to provide a comprehensive survivability assessment methodology for this type of structures.
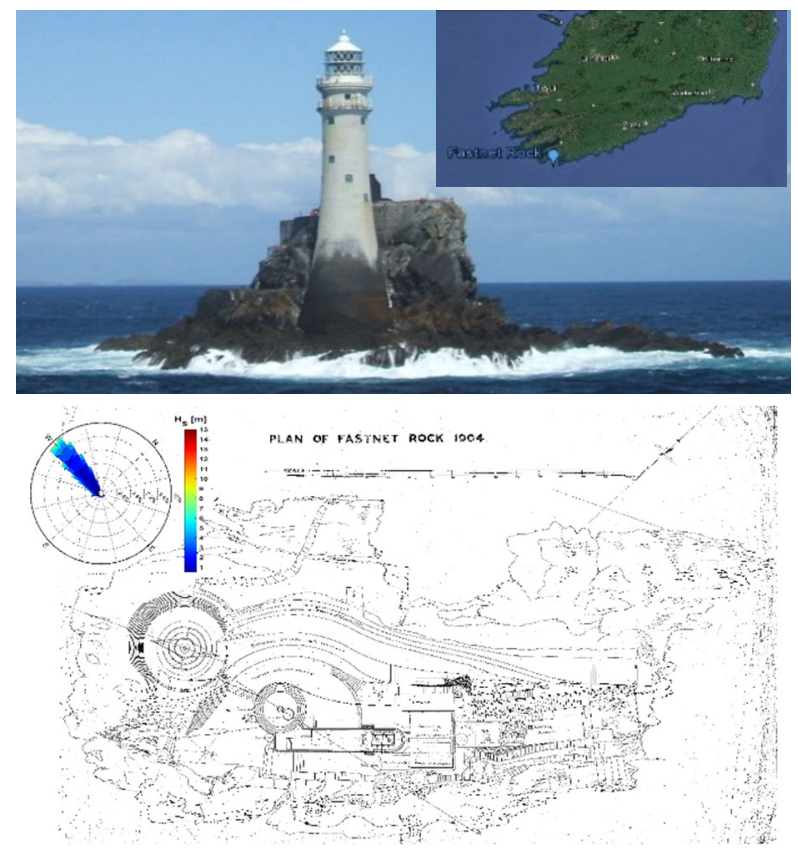

Figure 1 Fastnet rock lighthouse, location (inset) and directional wave climate

\section{METHODS}

Three main activities characterize the study:

1. Extreme analysis and impact wave loading description. Based on the Ifremer's hindcast model data (Boudière et al., 2013), directional extreme wave analysis is completed in order to provide a description of the extreme wave climate by means of a GPD-Poisson distribution (Figure 2, left). Breaking wave loadings are calculated conforming to the modified Wienke and Oumeraci's (2005) theory presented by Trinh et al. (2016) (Figure 2, right).
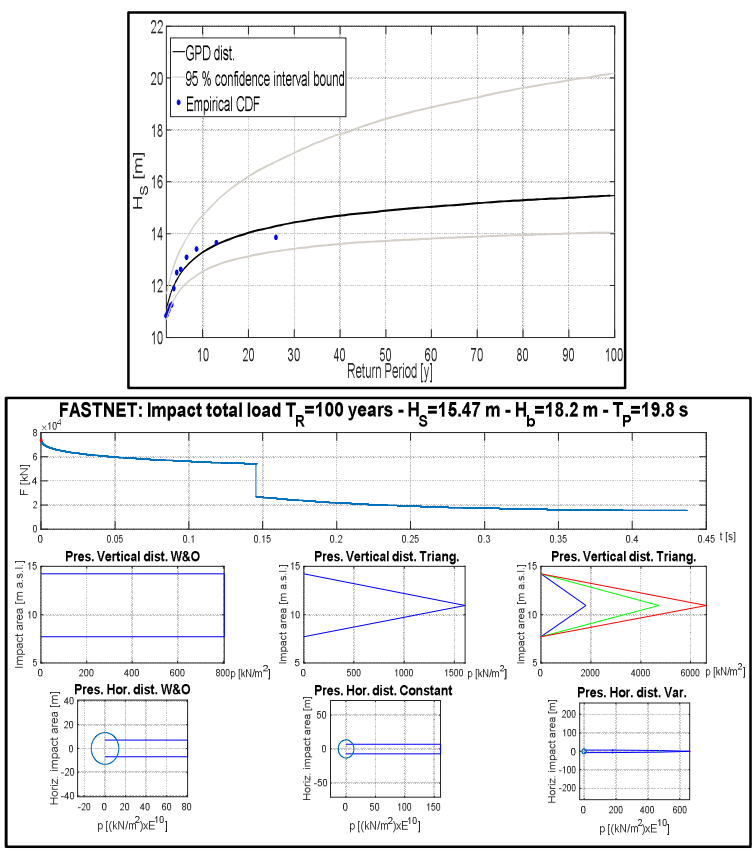

Figure 2 Left: Extreme wave climate - Right: Total impact load, vertical and horizontal pressure distributions

2. Field modal test.

Carrying equipment to an offshore lighthouse requires meticulous planning considering the limited space and lifting capacity of the helicopter. In particular the need for a mechanical shaker aimed to provide external input to the structure must be very carefully considered given the substantial weight of both shaker and amplifier. Due to space and weight limitations the number of accelerometers that could be used is limited, preventing the ideal solution of monitoring all lighthouse levels in both directions simultaneously. The main findings of this activity are in the form of sets of modal properties: i) natural frequencies, ii) damping ratios, iii) mode shapes and iv) modal masses (Figure 3 and Figure 4).

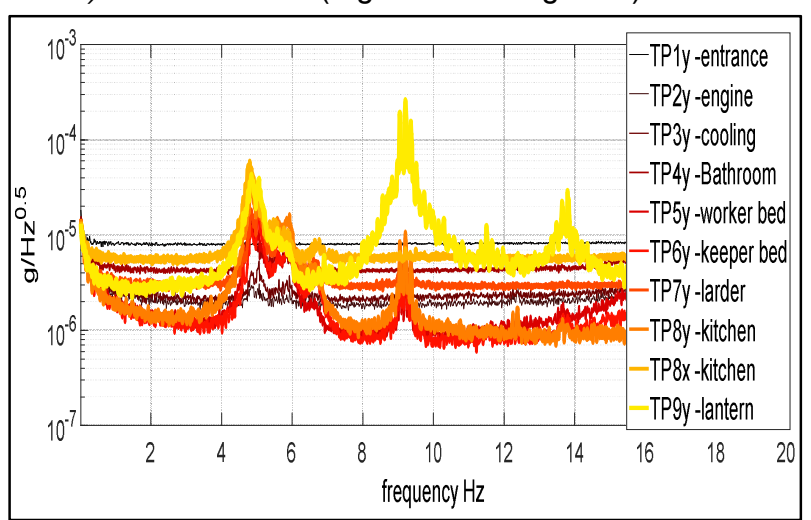




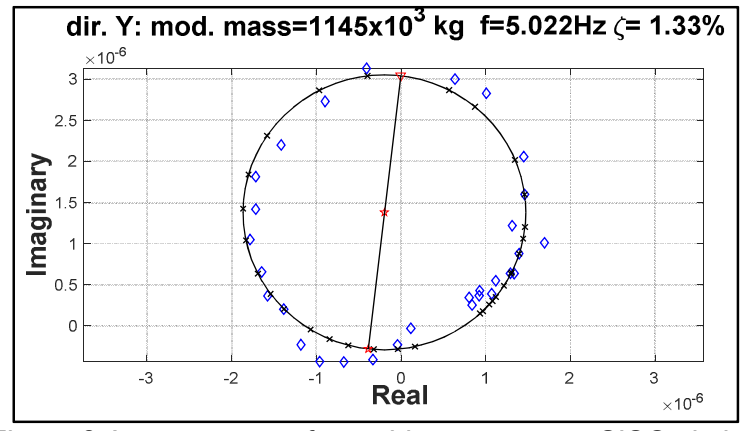

Figure 3 Auto-spectrum for ambient response, SISO circle fit for forced vibration test.

3. Structural numerical model.

The finite element numerical model is created with the software Abaqus 6.14 (2014). A structured and swept mesh with hexahedral (upper structure) and tetrahedral (complex broadening of the base area) elements are used for the model. Non-structural masses are added on the top stone course of the structure to simulate the lantern mass. The calibration of the numerical model is performed in terms of frequencies, mode shapes and modal masses, achieving very good correlation with the experimental dynamic identification (Figure 4). The survivability of the lighthouse is assessed based on its structural response to the impact load of the wave applied as a time-history sequence.
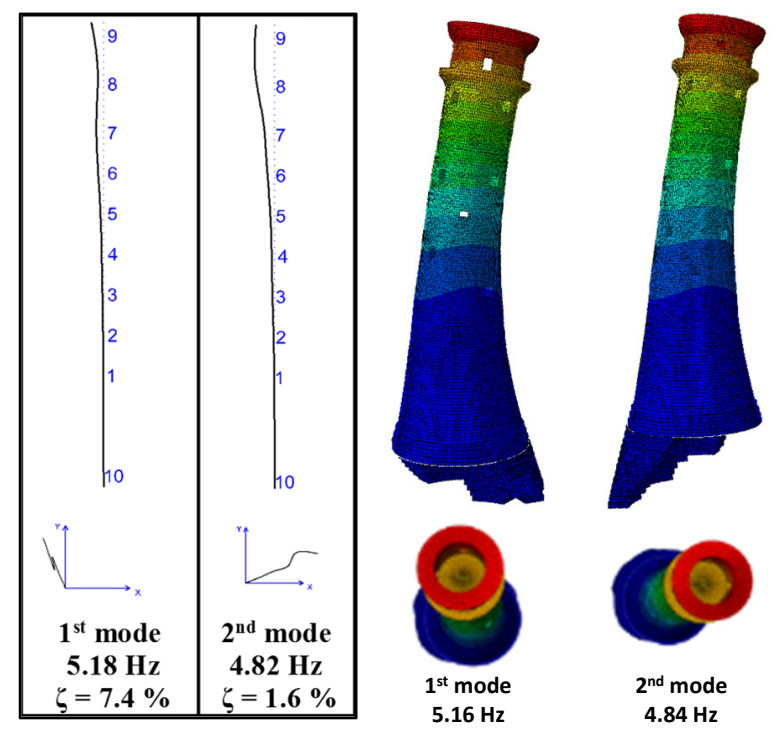

Figure 4 Experimental and numerical first and second

$$
\text { modes }
$$

\section{RESULTS}

The adopted multidisciplinary approach allows a comprehensive survivability assessment of this type of marine structures. Preliminary results of the study highlight the severity of the wave climate and its effects on the dynamic response of the lighthouse. Moreover, the importance of the elevation of the wave impact area is highlighted.

\section{REFERENCES}

Boudière, Maisondieu, Ardhuin, Accensi, PineauGuillou, Lepesqueur, (2013). A suitable metocean hindcast database for the design of Marine energy converters International Journal of Marine Energy, 34,e40-e52.

Wienke, and Oumeraci, (2005). Breaking wave impact force on a vertical and inclined slender pile-theoretical and large-scale model investigations. Coastal Engineering, 52, 435-462.

Trinh, Raby, Banfi, Corrado, Chiaia, Rafiq, Cali, (2016). Modellig the Eddystone Lighthouse response to wave loading. Engineering Structures, 125, 566-578. Abaqus, 2014. Abaqus documentation 6.14, Dassault Systèmes. 